\title{
Synthesis of metal nanoparticles in living plants
}

\author{
Luca Marchiol \\ Dipartimento di Scienze Agrarie e Ambientali, Università di Udine, Italy
}

\begin{abstract}
In recent years, nanotechnologies have evolved from a multidisciplinary research concept to a primary scientific field. Rapid growth of new technologies has led to the development of nanoscale device components, advanced sensors, and novel biomimetic materials. In addition to chemical and physical approaches a new, simple and cheaper strategy to synthesize metal nanoparticles utilizes biological tools such as bacteria, yeasts, fungi, and plants. The majority of research has investigated ex vivo synthesis of nanoparticles in plants, proving that this method is very cost effective, and can therefore be used as an economic and valuable alternative for the large-scale production of metal nanoparticles. Instead, very few studies have been devoted to investigating the potential of living plants. The synthesis of metal nanoparticles using living plants is discussed in this review. So far, metal NPs formation in living plants has been observed for gold, silver, copper and zinc oxide. To date the results achieved demonstrate the feasibility of this process; however several aspects of the plant physiology involved should be clarified in order to be able to gain better control and modulate the formation of these new materials. Plant sciences could significantly contribute to fully exploring the potential of phyto-synthesis of metal nanoparticles.
\end{abstract}

\section{Introduction}

Humanity has experienced several technological revolutions that have strongly influenced the course of history. The first (the Industrial Revolution), introduced the steam engine and steelmaking, the second

Correspondence: Luca Marchiol, Dipartimento di Scienze Agrarie e Ambientali, Università di Udine, via delle Scienze 208, 33100 Udine.

Tel. +39.0432.558611 - Fax +39.0432.558603.

E-mail: marchiol@uniud.it

Key words: Nanotechnology, nanoparticles, biosynthesis, plants.

Received for publication: 11 February 2012.

Accepted for publication: 24 April 2012.

CCopyright L. Marchiol, 2012

Licensee PAGEPress, Italy

Italian Journal of Agronomy 2012; 7:e37

doi:10.4081/ija.2012.e37

This article is distributed under the terms of the Creative Commons Attribution Noncommercial License (by-nc 3.0) which permits any noncommercial use, distribution, and reproduction in any medium, provided the original author(s) and source are credited. was promoted by the introduction of electricity on an industrial scale. Most recently we have had the Information Revolution, characterized by the widespread introduction of computing devices and the internet. Nanotechnology is widely considered to constitute the basis of the next technological revolution: the Nano Revolution (Ramsden, 2005).

The ideas and concepts behind nano science and nanotechnology began in late 1959 with a talk entitled There's Plenty of Room at the Bottom by physicist Richard Feynman at an American Physical Society conference, held at the California Institute of Technology in Pasadena, long before the term nanotechnology was used. Feynman described the theoretical basis of a process in which scientists would be able to manipulate and control individual atoms and molecules. About ten years later Professor Norio Taniguchi at Tokyo State University coined the term nanotechnology. In 1981, with the development of the scanning tunnelling microscope that could see individual atoms, modern nanotechnology was born.

Nanotechnology is a broad-based science involving manipulation of atoms, electrons, protons and neutrons in a variety of ways to generate new understanding of how materials can be developed to solve many problems in medicine, engineering, agriculture, biology, chemistry, surface science, space exploration, ocean and marine science, geography and geology. In some cases the research will develop new machines or ways to deliver new products (Kawazoe and Meeche, 2005).

The birth of a new field of science is always based on new theories and new concepts; new terms and definitions are also required. In brief, nanotechnology is the application of science to control matter at the molecular level. What the US National Nanotechnology Initiative calls nanotechnology involves all of the following: i) research and technology development at the atomic, molecular or macromolecular levels, in the length scale of approximately 1-100 nanometre (nm) range; ii) creating and using structures, devices and systems that have novel properties and functions because of their small and/or intermediate size; iii) ability to control or manipulate on the atomic scale.

The International Organisation for Standardisation (IS0, 2008) defines the term nanomaterial as material with any external dimensions in the nanoscale or having internal structure or surface structure in the nanoscale (size range approximately $1 \mathrm{~nm}$ to $100 \mathrm{~nm}$ ).

Following the recommendation by the European Commission (2011) nanomaterial means a natural, incidental or manufactured material containing particles, in an unbound state or as an aggregate or as an agglomerate and where, for $50 \%$ or more of the particles in the number size distribution, one or more external dimensions is in the size range $1 \mathrm{~nm}-100 \mathrm{~nm}$. Manufactured nanomaterials can be further grouped into four types (USEPA, 2007): i) carbon-based materials, usually including fullerenes, single walled carbon nanotube (SWCNT) and multi-walled carbon nanotube (MWCNT). These nanomaterials are composed mainly of carbon, most commonly taking the form of hollow spheres, ellipsoids, or tubes. Fullerenes are made of pure carbon, and represent a new carbon allotrope discovered in 1985 (Kroto et al., 1985); other well-known carbon allotropes are diamond and graphite. Spherical and ellipsoidal carbon nanomaterials are referred to as fullerenes, while cylindrical ones are called nanotubes. These particles have many potential applications, including improved films and coat- 
ings, stronger and lighter materials, and applications in electronics; ii) metal-based materials such as quantum dots, nanogold, nanozinc, nanoaluminum, and nanoscale metal oxides like $\mathrm{TiO}_{2}, \mathrm{ZnO}$ and $\mathrm{Al}_{2} \mathrm{O}_{3}$; a quantum dot is a closely packed semiconductor crystal comprised of hundreds or thousands of atoms, and whose size is in the order of a few $\mathrm{nm}$ to a few hundred $\mathrm{nm}$; iii) dendrimers, which are nano-sized polymers built from branched units capable of being tailored to perform specific chemical functions. The surface of a dendrimer has numerous chain ends, which can be tailored to perform specific chemical functions. Three-dimensional dendrimers contain interior cavities into which other molecules could be placed, with promising prospects for drug delivery; iv) composites, which combine nanoparticles with other nanoparticles or with larger, bulk-type materials.

The unique properties of these various types of intentionally produced nanomaterials give them novel electrical, catalytic, magnetic, mechanical, thermal, or imaging features that are highly desirable for applications in the commercial, medical, military, and environmental sectors.

Nanotechnology research spending worldwide expanded rapidly during the past decade. The US federal spending jumped from US $\$ 464$ million in 2001 to nearly $\$ 1.8$ billion in 2010. China, Germany, Japan and Korea soon followed in setting up national nanotechnology programmes, and the European Union (EU) designated nanotechnology as a research priority in 2002 . More than 60 countries now have national nanotechnology programmes. Global public investment in research and development (R\&D) in nanotechnology reached $\$ 8.4$ billion in 2008 , with a further $\$ 8.6$ billion of corporate funding (Shapira and Wang, 2010).

Nanotechnology has been defined a convergent science in the sense that it brings together different sciences and technologies into a single field. Indeed, many active fields in nanotechnology research demand an understanding of diverse areas of science (physics, chemistry, material science, biology, electrical/mechanical/chemical engineering). Porter and Youtie (2009) in the paper How interdisciplinary is nanotechnology? published in the Journal of Nanoparticles Research weighed up such convergence using a new map of science approach (Rafols and Meyer, 2010). It was confirmed that nano exhibits a high degree of disciplinary diversity, in fact nano publications cite, and therefore draw knowledge from, multiple disciplines.

\section{Nanoparticles}

Nanoparticles (NPs), abbreviate form of nano scale particles, are atomic or molecular aggregates with at least one dimension comprised between 1 and $100 \mathrm{~nm}$. NPs have attracted interest because of their small size, exhibition of emergent properties like quantum dots, nonlinear optical, thermal, electrical and chemical properties. A number of studies showed the importance of NPs to improve human health, electronic, magnetic and optoelectronic, biomedical, pharmaceutical, cosmetic, energy, environmental, catalytic and material applications (Youtie et al., 2008; Porter and Youtie, 2009).

When particle sizes of solid matter in the visible scale are compared to what can be seen under a regular optical microscope, there is little difference in the properties of the particles. But when particles are created with dimensions of about 1-100 nm, the materials' properties change significantly from those at larger scales. This is the size scale where quantum effects influence the behaviour and properties of particles. Since a nanoparticle has such a large surface area per unit mass, it interacts differently with other naturally occurring molecules than would a molecule made up of the same chemical elements at microscale. For instance, nanoscale carbon tubes, although composed of elemental carbon do not behave like graphite, which has the same composition. At the nanoscale, properties of materials - melting point, fluorescence, electrical conductivity, magnetic permeability, and chemical reactivity - are size-dependent (Grassian, 2008).

Depending on the origin we can distinguish three types of NPs: natural, incidental and engineered. Natural NPs have existed since the earth's beginnings and still occur in the environment in volcanic dusts and mineral composites. Incidental NPs are typically represented by engine exhaust particles, coal combustion, or other fraction or airborne combustion by-products. In urban areas, most nanoparticles come from diesel engines or cars with defective or cold catalytic converters (USEPA, 2007).

A wide variety of materials can be used to make these nanoparticles, such as metal oxide ceramics and silicates, magnetic materials, lyposomes, dendrimers, emulsions, etc. (Holister et al., 2003).

Engineered NPs are produced by a number of chemical and physical approaches summarized in Figure 1. Traditional technologies use a top-down approach when constructing materials. Most objects are created starting from a bulk materials and then breaking it into smaller pieces using mechanical, chemical or other forms of energy until they precisely form the desired construction (e.g. integrated circuits in microelectronics) (Kawazoe and Meech, 2005). Alternatively, the bottom-up approach recognizes that the building blocks of life (enzymes, and other components of each living cell), already act as machines at the nanoscale. Nanoscale materials are synthesised from atomic or molecular species via chemical reactions, allowing for the precursor particles to grow in size (Prathna et al., 2010).

However, such methods are harmful as the chemicals used are often toxic, flammable, not easily disposable due to environmental issues, have low production rate and are expensive (Kowshik et al., 2003). Striving for alternative and cheaper pathways for nanoparticle synthesis, scientists contributed to the development of a relatively new and largely unexplored area of research based on the biosynthesis of nanomaterials (Mohanpuria et al., 2008). A great deal of effort has been put into the search for methods utilizing biological systems in order to produce metal nanoparticles at ambient temperature and pressure without

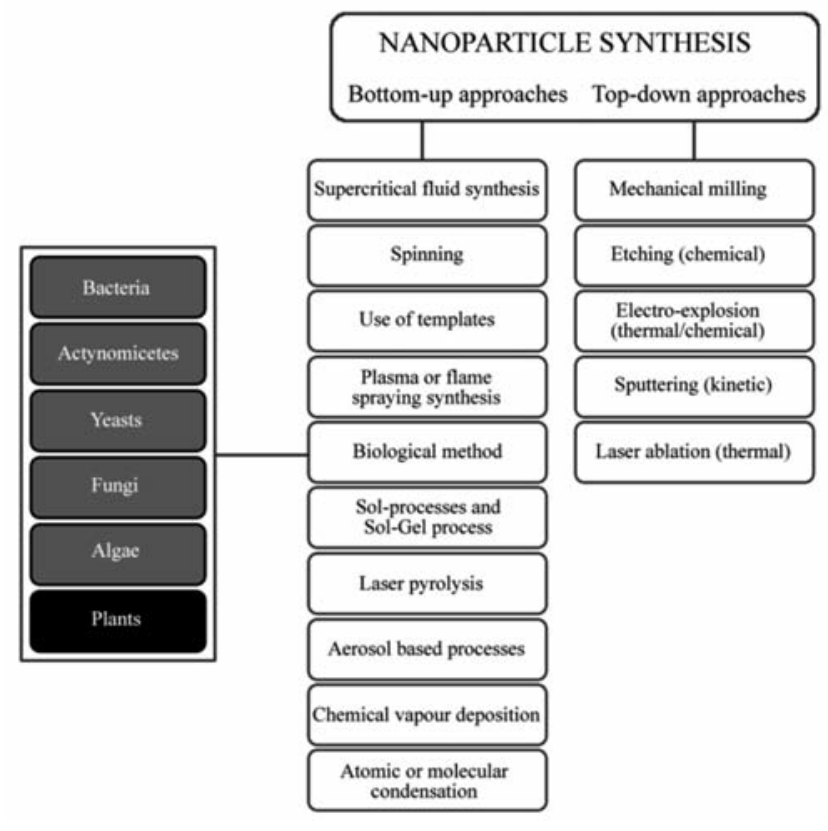

Figure 1. Methods for the preparation and manufacture of nanoparticles (redrawn from Iravani, 2011). 
requiring hazardous agents and generating poisonous by-products (Figure 1).

Biosynthesis of NPs is a type of bottom-up approach where the main reaction occurring is reduction/oxidation. Various micro-organisms such as bacteria, fungi, and yeasts have been suggested as nanofactories for intra- and extra-cellular synthesis of metals (Beveridge et al., 1980; Lovley et al., 1987; Ahmad et al., 2003; Husseiny et al., 2007; Singaravelua et al., 2007).

The use of plants for nanoparticle synthesis is a comparatively new and under-researched technique. Synthesis of metal NPs using plant extracts is very cost effective, so can be used as an economic and valid alternative for the large-scale production of metal nanoparticles (Huang et al., 2007).

The bioreduction of metal NPs by combinations of biomolecules found in plant extracts such as enzymes, proteins, amino acids, vitamins, polysaccharides, typically obtained by contact of a broth of plant leaves with metal salts, has been intensively investigated in recent years (Iravani, 2011). The efficient and rapid extracellular synthesis of $\mathrm{Ag}, \mathrm{Cu}$ and $\mathrm{Au}$ nanoparticles using broth extracts of several plants has been reported, such as Aloe vera (Chandran et al., 2006), Medicago sativa (Gardea-Torresday et al., 2002), Pelargonium graveolens (Shiv Shankar et al., 2003a, 2003b), Azadirachta indica (Shiv Shankar et al., 2004), Avena sativa (Armendariz et al., 2004a), wheat (Armendariz et al., 2004b), Tamarindus indica (Ankamwar et al., 2005a), lemongrass (Shiv Shankar et al., 2005), Emblica officinalis (Ankamwar et al., 2005b), Humulus lupulus (Rai et al., 2006), Spinacia oleracea and Lactuca sativa (Kanchana et al., 2011) and Capsicum annum (Jha and Prasad, 2011). For a more exhaustive list of plant species whose extracts have been used for metal nanoparticle production, refer to Narayanan and Sakthivel (2011).

According to Jha and Prasad (2011) such studies could prove to have an enormous impact in the immediate future if plant tissue culture and downstream processing procedures are applied in order to synthesize metallic as well as oxide nanoparticles on an industrial scale. If the majority of research has investigated ex vivo synthesis of NPs, very few studies have investigated the potential of living plants.

The phyto-synthesis of metal NPs using living plants is discussed in this review.

\section{Phyto-synthesis of metal nanoparticles}

All plants use their roots to extract water, nutrients and minerals, even heavy metals, from the soil they grow in. This principle is paradigmatic of phytoremediation, which is a method for removing contaminants from soils, and also possibly a way of producing NPs.

Both processes are based on metal-tolerance and resistance mechanisms, which allow certain plants to survive while accumulating high concentrations of metals (Goldsbrough, 2000). Such plants, typically represented by hyperaccumulators (Baker and Brooks, 1989), have the capacity to accumulate significant amounts of metals and compartmentalize them efficiently in the cell wall, vacuole, and to the specific compartments of the cytosol in order to render them nontoxic and keep them away from active metabolic sites in plant cells (Salt et al., 1998; Memon and Schröder, 2008). Other possible plant adaptive responses to metal stress include activation of alternative metabolic pathways less sensitive to metal ions, modification of enzyme structure, or alteration of membrane permeability by compositional changes (Baker, 1987).

Among the different phytoremediation techniques, phytomining is the most specialized. Phytomining involves growing hyperaccumulator plants on a mineralized soil or low-grade ore body and then harvesting and incinerating the produced biomass in order to produce a commer- cial bio-ore (Chaney, 1983; Anderson et al., 1999). Studies have shown that thallium and nickel are metals for which phytomining may also be economically viable using natural or non-induced hyperaccumulation (Robinson et al., 2009). Of course, the greatest interest for phytomining concerns the possibility of lowering the costs of recovering precious ( $\mathrm{Au}, \mathrm{Ag}$, and $\mathrm{Pt}$ ) or semi-precious elements ( $\mathrm{Ni}, \mathrm{Cu}, \mathrm{Zn}$ ).

Anderson et al. (1998) first described the hyperaccumulation of gold in plants; Indian mustard (Brassica juncea Czern.) plants, grown in pots filled with different auriferous substrates amended with ammonium thiocyanate as chelating agent, were induced to accumulate gold concentrations in leaf tissues as high as $57 \mathrm{mg} \mathrm{kg}^{-1}$ in dry matter. Working with dead plant biomasses, Gardea-Torresdey et al. (1999) demonstrated the ability of alfalfa (Medicago sativa L.) tissues (roots and shoots) to bind gold(III) in aqueous solutions where the gold(III) ions were reduced to gold $^{(0)}$ by the plant biomass. The gold solutions that reacted with the alfalfa biomass were observed to turn purple, thus suggesting metal reduction. Transmission electron microscopy (TEM) observation later confirmed the presence of colloidal gold ${ }^{(0)}$, confirming also that plant biomass was able to reduce gold by a mechanism which yielded colloids of different shapes and sizes (Gardea-Torresdey et al., 1999).

Taking origin from these observations, the biosynthesis of metal NPs from vascular plants has become one of the exciting research fields in the burgeoning area of materials science. Some principles of phytoremediation have been considered useful to be applied in nanotechnology. While many studies have looked at metal uptake by plants, particularly with regard to phytoremediation and hyperaccumulation, and a few have distinguished between elemental metal deposition $\left(\mathrm{M}^{0}\right)$ and metal salt accumulation ( $\mathrm{Mx}$ ), quantification of the proportion of the salts converted to metal nanoparticles has only rarely been addressed (Gardea-Torresdey et al., 2005; Marshall et al., 2007). On the other hand, powerful investigation techniques have only become available in the last decade, allowing more detailed studies on metal compartmentalization in plant tissues.

The advent of analytical instrumentation such as proton induced Xray emission (PIXE), X-ray absorption spectroscopy (XAS) and synchrotron X-ray fluorescence (SXRF) spectroscopy has made it possible to observe and accurately describe the form and distribution of metals within a plant (Mesjasz-Przybylowicz et al., 2001a, 2001b; McNear et al., 2005) and valence state and size of the accumulated metal NPs (Narayanan and Sakthivel, 2011).

\section{The mechanism of metal nanoparticle formation in plants}

The exact mechanism for the formation of nanoparticles in living plants is not yet known, nor investigated in depth (Rai et al., 2008; Haverkamp and Marshall, 2009). The process, conceptually, appears to be close to the mechanisms of biomineralization.

Biomineralization, or the precipitation of minerals as a result of the metabolic functioning of a living organism, is a process present in all five kingdoms of nature, and is widely practiced by plants. The process creates heterogeneous accumulations, composites composed of biological (or organic) and inorganic compounds, with inhomogeneous distributions that reflect the environment in which they form (Mann, 1996; Skinner and Jahren, 2003).

Minerals produced by biologically induced and controlled mineralization processes in living organisms are: carbonates, phosphates, sulphates and sulphides, hydrate silica, metals, oxides, hydroxides and organic minerals. In higher plants mostly calcium oxalate and silica are present (Weiner and Dove, 2003). In biosilicification it was suggested that silicic acid is taken up through the plant roots and transported as 
a silicon complex through the xylem. When this complex reaches the stems or leaves, where mineral deposition should occur, its breakdown is triggered by change in $\mathrm{pH}$, inducing the release of silicic acid that will further condense to form the silica (Kaufman et al., 1989). However, more complex molecules such as proteins act as regulators of the systems. Perry and Keeling-Tucker (2003) demonstrated that proteins and proteoglycans have a role in the catalysis of silica polycondensation and in structure direction during the formation of silica structures in Equisetum telmateia.

Although the dynamics of NPs formation in living plants has not yet been understood, some general principles have been clarified. To be able to produce and store metal NPs in the tissues a plant must have the element in bioavailable form in the growth medium. Subsequent to root uptake the element is transported across the root membrane and translocated within the plant (Haverkamp and Marshall, 2009). Once transported into the plants, the reduced metals are deposited in nanoparticles of various shapes and sizes. Actually, it is still under discussion whether NPs are formed outside the plant and then transported through the root membrane into the plant (Gardea-Torresdey et al., 2003; Sharma et al., 2007), or whether NPs are formed within the plant by the reduction of the metal salt (Haverkamp et al., 2007). The most reliable hypothesis is that the ionic form of the element must be transported across the root membrane, then translocated in the plant and reduced to the elemental form (Gardea-Torresdey et al., 2005).

As occurred in biosilicification, proteins also play an important role in NPs formation in plant tissues. Chandran et al. (2006) verified the active role played by proteins in Ag reduction and formation of NPs in extracts of Capsicum annuum. The extracts of such species contains a lot of biomolecules, such as proteins/enzymes, polysaccharides, amino acids and vitamins, etc. (Jagadeesh et al.; 2004; Collera-Zuniga et al., 2005) which could be used as reductants to react with silver ions, leading to AgNPs synthesis in solutions (Li et al., 2007).

\section{Factors influencing nanoparticles formation in plants}

Several factors influence the reduction process of metal ions into NPs. The (nano) environmental conditions determine the average size and size distribution of NPs, which is a very important feature for technological use of such materials. However, very little has so far been elucidated for living plants. A better understanding of the mechanisms of the process will therefore improve the ability to control and modulate the process of NPs in living plants. The influence of some environmental parameters on the NPs formation process discussed in some papers are briefly presented in the following sections.

\section{Values of $\mathrm{pH}$ and temperature}

The $\mathrm{pH}$ value of the medium influences the size of nanoparticles under formation in both extracts and living plants. Studies by GardeaTorresdey et al. (1999) with alfalfa biomass indicated that $\mathrm{pH}$ is an important factor in the bioformation of colloidal gold. Armendariz et al. (2004a) studied AuNPs formation using biomass of Avena sativa; they reported that the size of AuNPs can be controlled by altering the $\mathrm{pH}$ of the medium. The adsorption of Au ions to alfalfa biomass was shown to be independent of the initial solution $\mathrm{pH}$. However, the resulting nanoparticle size greatly varied with $\mathrm{pH}$.

One of the most interesting aspects of NPs biosynthesis is the fact that this process occurs at ambient temperature. However, the temper- ature of the reaction medium is a critical factor that determines the nature of nanoparticles formed; Rai et al. (2006) studying AuNPs formation using the leaf extract of Cymbopogon flexuosus demonstrated that at higher temperatures, the percentage of gold nanotriangles relative to spherical particles is significantly reduced, whereas lower reaction temperatures mostly promote nanotriangle formation.

\section{Source of metals and exposure time}

Data recently provided by Haverkamp et al. (2011) demonstrated that the process of NPs formation in planta is significantly influenced by the source of metals. Working on Brassica juncea, they tested whether the use of different complexes of Ag provides some control over NPs size. Actually, plants supplied with $\mathrm{AgNO}_{3}$ produced $\mathrm{Ag} \mathrm{NPs}$ of $10-35 \mathrm{~nm}$, whereas when $\mathrm{Ag}$ was supplied as a complex, $\mathrm{Ag}\left(\mathrm{NH}_{3}\right)^{2+}$ and $\mathrm{Ag}\left(\mathrm{S}_{2} \mathrm{O}_{3}\right)_{2}{ }^{3+}$, AgNPs were observed with a size of about $2 \mathrm{~nm}$. Moreover, about $50 \%$ of simple $\mathrm{Ag}^{+}$ions were reduced to $\mathrm{Ag}^{0}$, while only $30 \%$ and $10 \%$ of $\mathrm{Ag}\left(\mathrm{NH}_{3}\right)^{2+}$ and $\mathrm{Ag}\left(\mathrm{S}_{2} \mathrm{O}_{3}\right)_{2}{ }^{3+}$ were transformed, respectively. These differences in the proportion or the absolute amount of the salts could be due to the different reduction potentials for each of these salts.

A study evaluating the effects of several environmental parameters on nucleation and growth of AuNPs in some plant species was done by Starnes et al. (2010). Seedlings of Medicago sativa, Cucumis sativus, Origanum vulgare, Trifolium pratense, Lolium multiflorum and Helianthus annuus were hydroponically grown, supplied with $50 \mathrm{ppm}$ $\mathrm{KAuCl}_{4}$ and harvested sequentially over a period of time $(6 \mathrm{~h}, 12 \mathrm{~h}, 1 \mathrm{~d}$, $3 \mathrm{~d}, 5 \mathrm{~d}$, and $7 \mathrm{~d}$ ). It was concluded that manipulation of growth conditions triggered a noticeable shift in the relative abundance of spherical, triangular, hexagonal, and rectangular AuNPs, providing the first empirical evidence about the feasibility of in planta NPs engineering.

\section{Reducing agents}

Among the various categories of compounds synthesized in plants that have potent biological activities, phytochemicals (primary and secondary metabolism products, such as antioxidants, flavonoids, flavones, isoflavones, catechins, anthocyanidins, isothiocyanates, carotenoids, polyphenols) are known as an important natural resource for the synthesis of metallic nanoparticles (Park et al., 2011).

A large number of papers have been published on the biosynthesis of nanoparticles using the phytochemicals contained in the extracts of a number of plant species (Haverkamp, 2011). On the contrary, little has been understood about this process in living plants. Beattie and Haverkamp (2011) recently investigated the location of Au and AgNPs formation within the tissues of Brassica juncea with the aim of clarifying the mechanisms of NPs formation. A couple of experimental observations were recorded. First, it was found that the sites of the most abundant reduction of metal salts to nanoparticles were the chloroplasts, in which high reducing sugars (glucose and fructose) are responsible for the reduction of Au and Ag. Second, a direct quantitative relationship between the amount of reducing sugar present, or produced, and the quantity of metal nanoparticles formed, confirmed the process.

\section{Plant species and growth stage}

A study by Rodriguez et al. (2007) reported the capability of the desert plant Chilopsis linearis (desert willow) to uptake gold (Au) from gold- 
enriched media at different plant growth stages. Plants were exposed to $20,40,80,160$, and $320 \mathrm{mg} \mathrm{L}^{-1} \mathrm{Au}$ in agar-based growing media for 13, 18,23 , and $35 \mathrm{~d}$, respectively. Gold concentrations in plant tissues increased over time, demonstrating Au uptake, however plant growth was unaffected. The XAS data indicated that Chilopsis linearis produced gold nanoparticles within the plant tissues. Plants exposed to $160 \mathrm{mg} \mathrm{L}^{-1}$ Au formed AuNPs that averaged approximately 8, 35, and $18 \AA$ ( $1 \AA=0.1$ $\mathrm{nm}$ ) in root, stem, and leaves, respectively. It was observed that the average size of the Au nanoparticles formed by the plants is related to the total Au concentration in tissues and their location in the plant.

A more recent paper that deals with different plant species has previously been mentioned (Starnes et al., 2010).

\section{Nanoparticles formation in living plants: state of the art}

In this section other important papers on NPs formation in living plants are reviewed, with the fundamental data summarized in Table 1. Papers already mentioned will not be further cited. The research group led by Jorge Gardea-Torresdey at the University of Texas (El Paso) first showed that gold accumulates in plant tissues can be present as discrete metallic particles of nanometre scale. Seeds of alfalfa were germinated on an agar medium enriched with $320 \mathrm{mg} \mathrm{kg}^{-1} \mathrm{AuCl}_{4}$. After two weeks of growth the alfalfa plants were harvested and analyzed using XAS and TEM. Gold nanoparticles of 2 to $20 \mathrm{~nm}$ diameter were observed preferentially distributed in certain zones of the plant although the tissues for storage were not identified. The authors of this study assumed that the differences in particle size indicated growth of nanoparticles over time. Four nm diameter particles had an icosahedral structure, whereas particles of 6-10 nm diameter showed face centred cubic twinned structures (Gardea-Torresday et al., 2002).

In a similar study Gardea-Torresday et al. (2003) demonstrated the formation of Ag-NPs, as well as atomic wires or clusters, in alfalfa plants grown on $\mathrm{Ag}$ enriched agar. The source of silver ions in this study was supplied as silver nitrate $\left(\mathrm{AgNO}_{3}\right)$ at $0,40,80,160$, and 320 ppm, respectively. Ag-NPs ranging between 2 and $4 \mathrm{~nm}$ in size were found to have an icosahedral structure that corresponds to the lowest energy configuration for this size. The arrangement of atoms inside the nanoparticles was very disordered, perhaps indicating that the aggregation process could be very fast.

Confirmation of synthesis of plant-mediated Au-NPs was provided by Sharma et al. (2007), who demonstrated the uptake of high amounts of gold ${ }^{\text {(III) }}$ ions with subsequent reduction to $\mathrm{Au}^{(0)}$ inside plant cells or tissues by Sesbania drummondii (a leguminous shrub). The X-ray absorption spectroscopy near edge structure (XANES) and the extended X-ray absorption spectroscopy fine structure (EXAFS) demonstrated a high degree of efficiency for the biotransformation of $\mathrm{Au}^{(\mathrm{III})}$ into $\mathrm{Au}^{(0)}$ with the formation and growth of spherical Au-NPs of 6-20 nm.

The phyto-synthesis of mixed metal nanoparticles, perhaps even those difficult to synthesise by traditional methods, was demonstrated by Haverkamp et al. (2007) working with Brassica juncea. Plants were grown for 9 weeks on an Au-Ag-Cu enriched agricultural soil. Post-harvest dried plant tissues contained 760, 730 and $300 \mathrm{ppm}$ of $\mathrm{Au}, \mathrm{Ag}$ and $\mathrm{Cu}$, respectively. A STEM-EDX (EDX, energy dispersive X-ray spectroscopy) map for $\mathrm{Au}, \mathrm{Ag}$ and $\mathrm{Cu}$ was also recorded from which it was apparent that all three elements were present in all particles. In other words, the plant-mediated process produced an alloy. This result supports the hypothesis that it should be possible to produce a large range of alloys from many metals by a similar route, with substantial control over the composition of these alloys.

A hydroponic study by Harris and Bali (2008) provided confirmation of the ability of Ag uptake by $B$. juncea and alfalfa. However the species behaved differently. In fact the correlation among exposure time, substrate silver concentration and silver uptake was not consistent in $B$. juncea, whereas it was in alfalfa. However, after $72 \mathrm{~h}$ exposure to a solution of $\mathrm{AgNO}_{3}$ at $10,000 \mathrm{ppm}$, TEM images and PIXE spectroscopy showed the production of large quantities of Ag-NPs with a mean size of $50 \mathrm{~nm}$.

A very similar work, done by the same research group, was performed on the same species exposed to Au. In particular, the effects were investigated of exposure time $(24,48$, and $72 \mathrm{~h})$ at $1000 \mathrm{ppm}$ $\mathrm{KAuCl}_{4}$ on Au-NPs formation. In B. juncea and alfalfa across all concentrations and exposure times, a change in root colour from white to purple was observed, indicative of the formation of $\mathrm{Au}^{(0)}$ nanoparticles within the root structure. TEM images of cross sections of the roots and shoots of both plants revealed the presence of large quantities of nanoparticles in varying sizes and shapes. A significant number of particles were observed in the root cell walls of both species, consistent with previous research by Nishizono et al. (1998) and GardeaTorresdey et al. (2002) and suggesting that heavy metals are immobilized in the root cell walls. In general, particle sizes varied in the range $2-2,000 \mathrm{~nm}$ and 2-1,000 nm in B. juncea and alfalfa, respectively. Root located Au-NPs had similar size distributions in both species, whereas the distribution within aboveground tissues was different, with $B$. juncea showing a much broader range of particle sizes (Bali and Harris, 2010).

Lastly, a method is required to extract the biologically produced metal NPs. While concentration of NPs produced from plant broths is simple, no method to extract NPs from living tissues is currently available. The metal fraction should be extracted from harvested plant biomass. Obviously incineration should be avoided, otherwise fusion or sinterization occurs causing the loss of the shape and size of NPs and hence their properties. A low temperature method is therefore necessary.

Marshall et al. (2007) studied the utilization of the enzyme 1- $\beta$ endogluconase from Trichoderma viridae to digest tissues of $B$. juncea in order to concentrate AuNPs. The AuNPs produced by plants, grown on soil with $22-48 \mathrm{ppm} \mathrm{Au}$, had a diameter of $5-50 \mathrm{~nm}$ at concentrations of 760-1,120 ppm Au.

\section{Prospects of agriculture advancement}

The field of nanotechnology is fast-growing and, beyond the results already achieved in related sciences, full of promising prospects, some of which are probably not yet imagined, with applications in medicine, consumer goods, heavy industry, information and communication technologies, optoelectronic devices, and environmentally-friendly energy systems.

Nanotechnology has the potential to revolutionize agriculture and food systems. Even though the agro-industry is just beginning to explore its applications, nanotechnology has exhibited great potential with new tools for the molecular treatment of diseases, weed control and enhancing the ability of plants to absorb nutrients (Jha et al., 2011).

The principle that underlay the so-called smart delivery systems already allows different applications. This is an innovative strategy of agrochemicals administration calibrated directly on the target rather than non-generically on the environment, in order to improve the effectiveness of the distribution of pesticides and fertilizers reducing collateral damage. Many of the world's leading agrochemical companies firms are conducting R\&D on the development of formulations which contain nanoparticles that are able to dissolve in water more effectively than existing ones, thus increasing their activity. Other products employ suspensions of nanoscale particles, which can be either water 


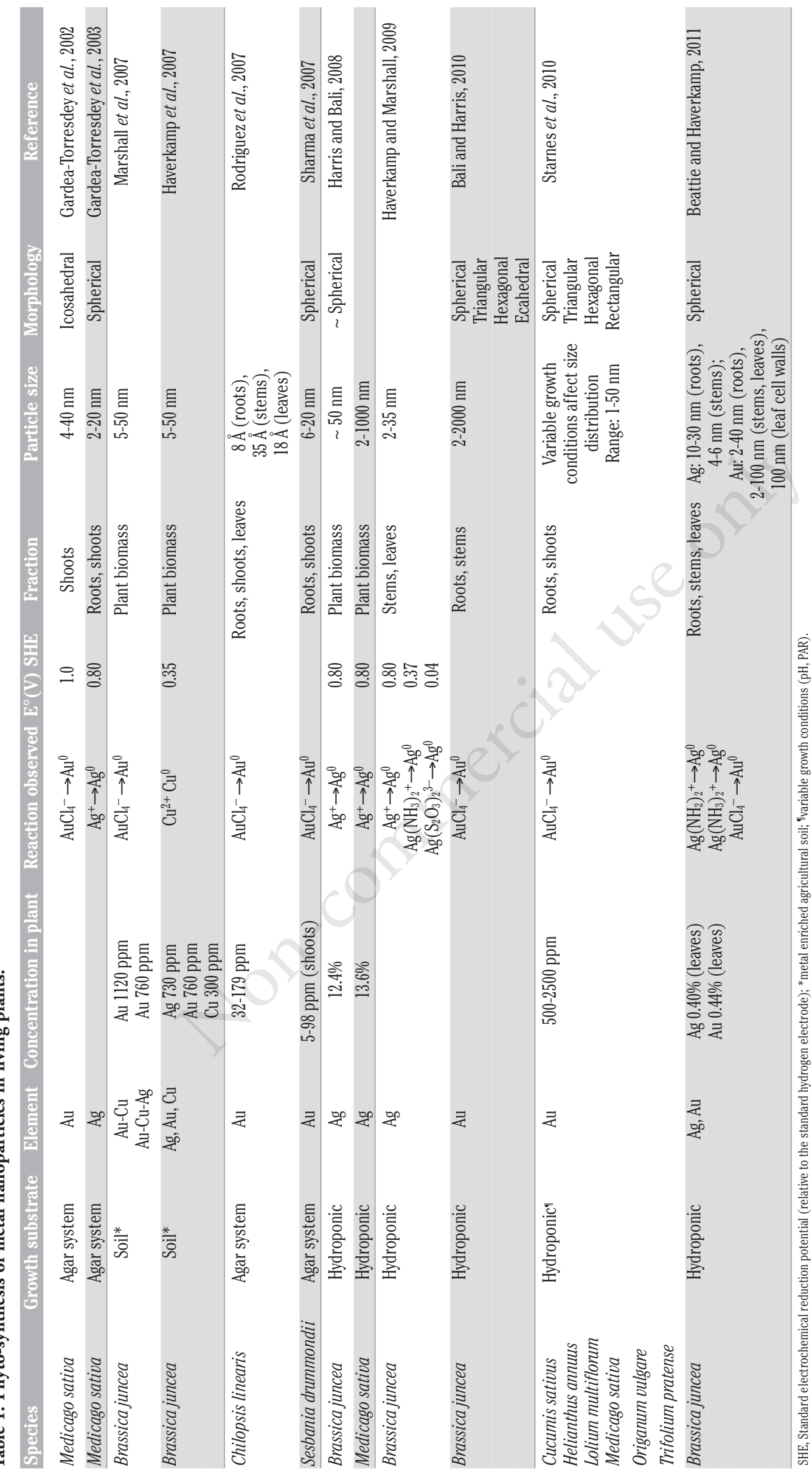


or oil-based and contain uniform suspensions of pesticidal or herbicidal nanoparticles (Sharon et al., 2010). It is clear that these systems require a sophisticated adjustment so that their operation is synchronized with the cycle of pathogens, with the phenological stage of weeds, thus avoiding the biological barriers of the target. It might also be possible to develop an agrochemical containing different substances for different functions (plant protection, fertilization, hormones, etc.) and encapsulated separately to avoid interactions between them and degradation. In this way, nanoparticles can serve as magic bullets containing herbicides, chemicals, or genes, which target particular plant parts to release their content. Moreover, several substances could be applied with the same treatment to the crop, and the nanocapsules could be regulated to release their load according to the characteristic of every loaded substance. Different active substances (for example, different herbicides) with a synergistic effect could be applied separately with the same treatment and released inside the parasite tubercles, so acting more effectively without harming the crop. For example, glyphosate, imidazolinones and sulfonylureas might be encapsulated separately within a polymeric shell. The shell would be functionalized with surfactants to improve the penetration through the cuticle, and applied systemically through the leaves. Thus, three herbicides with two different modes of action might be used with the same treatment. In addition, a residual effect in the soil would be avoided (Perez-Luque and Rubiales, 2008). Ideally, the concept of smart delivery system might be applied to plant nutrition. Nanotechnology could provide nano-fertilizers able to synchronize the release of nutrients with their crop uptake, thus avoiding nutrient losses and reducing the risks of groundwater pollution. Moreover, the nano-fertilizers should release the nutrients on-demand while preventing them from prematurely converting into chemical/gaseous forms that cannot be absorbed by plants. This can be achieved by preventing nutrients from interacting with soil, water and microorganisms, and releasing nutrients only when they can be directly internalized by the plant. In conclusion, returning to NPs, one among many tools employed in nanotechnology, so far metal NPs formation in living plants has been observed only for gold, silver, copper, an alloy of gold-silver-copper, and zinc oxide. Plant sciences could significantly contribute to fully exploring the potential of phyto-synthesis of metal NPs. It is fundamental to better understand the role of the physical and chemical parameters that modulate the process; however several aspects of plant physiology involved in the phenomenon should be clarified. From a physiological point of view, once the metal ions have been transported into the plant roots some questions remain to be answered. To date is not clear what determines the amount of metal that is deposited as NPs in plant tissues and especially, if there is an upper limit to this. So far researchers have investigated few plant species. The most studied ones being Medicago sativa and Brassica juncea, both considered as model species, and the latter as hyperaccumulator. Some other species have been studied recently. However, a systematic study about the potential of metal tolerant plants is currently lacking, although it is likely that such plants have more capacity to manage the phyto-synthesis of metal nanoparticles. In the near future it is expected that research efforts will be oriented in these directions, resolving such still open questions and thereby reinforcing the perspectives of the contribution of the plant sciences to nanotechnology.

\section{References}

Ahmad A, Senapati S, Khan MI, Kumar R, Sastry M, 2003. Extracellular biosynthesis of monodisperse gold nanoparticles by a novel extremophilic actinomycete Thermomonospora sp. Langmuir 19:3550-3553.
Anderson CWN, Brooks RR, Chiarucci A, LaCoste CJ, Leblanc M, Robinson BH, Simcock R, Stewart RB, 1999. Phytomining for nickel, thallium and gold. J. Geochem. Explor. 67:407-415.

Anderson CWN, Brooks RR, Stewart RB, Simcock R, 1998. Harvesting a crop of gold in plants. Nature 395: 553-554.

Ankamwar B, Chaudhary M, Sastry M, 2005a. Gold nanotriangles biologically synthesized using tamarind leaf extract and potential application in vapor sensing. Synth. React. Inorg. Met-Org. NanoMet. Chem. 35:19-26.

Ankamwar B, Damle C, Ahmad A, Sastry M, 2005b. Biosynthesis of gold and silver nanoparticles using Emblica officinalis fruit extract, their phase transfer and transmetallation in an organic solution. J. Nanosc. Nanotechnol. 5:1665-1671.

Armendariz V, Herrera I, Peralta-Videa JR, Jose-Yacaman M, Troiani H, Santiago P, Gardea-Torresdey JL, 2004a. Size controlled gold nanoparticle formation by Avena sativa biomass: use of plants in nanobiotechnology. J. Nanopart Res. 6:377-382.

Armendariz V, Jose-Yacaman M, Moller AD, Peralta-Videa J, Troiani H, Herrera I, Gardea-Torresday JL, 2004b. HRTEM characterization of gold nanoparticles produced by wheat biomass. Revista Mexicana De Fisica 50(Suppl.1):7-11.

Baker AJM, 1987. Metal tolerance. New Phytol. 106(Suppl.1):93-111.

Baker AJM, Brooks RR, 1989. Terrestrial higher plants which hyperaccumulate chemical elements - a review of their distribution, ecology and phytochemistry. Biorecovery 1:81-126.

Bali R, Harris AT, 2010. Biogenic synthesis of Au nanoparticles using vascular plants. Ind. Eng. Chem. Res. 49:12762-12772.

Beattie IR, Haverkamp RG, 2011. Silver and gold nanoparticles in plants: sites for the reduction to metal. Metallomics 3:628-632.

Beveridge TJ, Murray RGE, 1980. Sites of metal deposition in the cell wall of Bacillus subtilis. J. Bacteriol. 141:876-887.

Chandran SP, Chaudhary M, Pasrichia R, Ahmad A, Sastry M, 2006. Synthesis of gold nanotriangles and silver nanoparticles using Aloe vera plant extract. Biotechnol. Prog. 22:577-583.

Chaney RL, 1983. Plant uptake of inorganic waste constituents. In: J.F. Parr, P.B. Marsh and J.M Kla (eds.) Land treatment of hazardous wastes. Noyes Data Corp., New York, USA, pp 55-60.

Collera-Zuniga 0, Jimenez FG, Gordillo RM, 2005. Comparative study of carotenoid composition in three mexican varieties of Capsicum annuum L. Food Chem. 90:109-114.

DeRosa MC, Monreal C, Schnitzer M, Walsh R, Sultan Y, 2010. Nanotechnology in fertilizers. Nature Nanotech 5:91.

European Commission, 2011. Commission recommendation of 18 October 2011 on the definition of nanomaterial. In: Official Journal, L 275, 20/10/2011, pp 38-40. Available from: http://ec.europa.eu/environment/consultations/pdf/recommendation_nano.pdf

Gardea-Torresdey JL, Tiemann KJ, Gamez G, Dokken K, Pingitore NE, 1999. Recovery of gold(III) by alfalfa biomass and binding characterization using X-ray microfluorescence. Adv. Environ. Res. 3:8393.

Gardea-Torresday JL, Gomez E, Parsons JG, Peralta-Videa JR, Santiago P, Torresday KJ, Troiani HE, Yacaman MJ, 2002. Formation and growth of $\mathrm{Au}$ nanoparticles inside live alfalfa plants. Nano Lett. 2:397-401.

Gardea-Torresday JL, Gomez E, Peralta-Videa JR, Parsons JG, Troiani HE, Yacaman MJ, 2003. Alfalfa sprouts: a natural source for the synthesis of silver nanoparticles. Langmuir 19:1357-1361.

Gardea-Torresdey J, Rodriguez E, Parsons JG, Peralta-Videa JR, Meitzner G, Cruz-Jimenez G, 2005. Use of ICP and XAS to determine the enhancement of gold phytoextraction by Chilopsis linearis using thiocyanate as a complexing agent. Anal. Bioanal. Chem. 382:347-352.

Goldsbrough P, 2000. Metal tolerance in plants: the role of phy- 
tochelatins and metallothioneins. In: N. Terry and G. Ban elos (eds.) Phytoremediation of contaminated soil and water. Lewis Publ., Boca Raton, USA, pp 221-234.

Grassian VH, 2008. When size really matters: size-dependent properties and surface chemistry of metal and metal oxide nanoparticles in gas and liquid phase environments. J. Phys. Chem. C. 112: 1830318313.

Harris AT, Bali R, 2008. On the formation and extent of uptake of silver nanoparticles by live plants. J. Nanopart. Res. 10:691-695.

Haverkamp RG, 2011. Silver nanoparticles produced by living plants and by using plant extracts. In: I.A. Golubev (ed.) Handbook of phytoremediation. Nova Publ., New York, USA, pp 691-707.

Haverkamp RG, Agterveld DV, Marshall AT, 2007. Pick your carats: nanoparticles of gold-silver copper alloy produced in vivo. J. Nanopart. Res. 9:697-700.

Haverkamp RG, Marshall AT, 2009. The mechanism of metal nanoparticle formation in plants: limits on accumulation. J. Nanopart. Res. 11:1453-1463.

Holister P, Weener JW, Román CV, Harper T, 2003. Nanoparticles. Technol. White Papers 3:1-11.

Huang J, Li Q, Sun D, Lu Y, Su Y, Yang X, Wang H, Wang Y, Shao W, He $\mathrm{N}$, Hong J, Chen C, 2007. Biosynthesis of silver and gold nanoparticles by using novel sun-dried Cinnamomum camphora leaves. Nanotechnol. 18:105104.

Husseiny MI, AbdEl-Aziz M, Badr Y, Mahmoud MA, 2007. Biosynthesis of gold nanoparticles using Pseudomonas aeruginosa. Spectrochim. Acta A 67:1003-1006.

ISO, 2008. Nanotechnologies - Terminology and definitions for nanoobjects - Nanoparticle, nanofibre and nanoplate. ISO/TS 27687:2008.

Iravani R, 2011. Green synthesis of metal nanoparticles using plants. Green Chem. 13:2638-2650.

Jagadeesh BH, Prabha TN, Srinivasan K, 2004. Activities of -hexosaminidase and -mannosidase during development and ripening of bell capsicum (Capsicum annuum var. variata). Plant Sci. 167: 1263-1271.

Jha AJ, Prasad K, 2011. Green fruit of chili (Capsicum annum L.) synthesizes nano silver. Dig. J. Nanomater. Bios. 6:1717-1723.

Jha Z, Behar N, Sharma SN, Chandel G, Sharma DK, Pandey MP, 2011. Nanotechnology: prospects of agricultural advancement. Nano Vision 1:88-100.

Kanchana A, Agarwal I, Sunkar S, Nellore J, Namasivayam K, 2011. Biogenic silver nanoparticles from Spinacia oleracea and Lactuca sativa and their potential antimicrobial activity. Dig. J. Nanomater. Bios. 6: 741-1750.

Karn B, Kuiken T, Otto M, 2009. Nanotechnology and in situ remediation: A review of the benefits and potential risks. Env. Health Persp. 117:1823-1831.

Kaufman PB, Dayanandan P, Takeoka Y, Bigelow WC, Jones JD, Iler RK, 1981. Silica in shoots of higher plants. In: T.L.S. Simpson and B.E. Volcani (eds.) Silicon and siliceous structures in biological systems. Springer Verlag, New York, USA, pp 409-449.

Kawazoe Y, Meech JA, 2005. Welcome to IPPM'03-Nanotechnology: Do good things really come in small packages? Proc. 4th Int. Conf. Intelligent Processing and Manufacturing of Materials. J. Meech, Y. Kawazoe, V. Kumar, J.F. Maguire (eds.). DSEtech Publications, Inc. Lancaster, PA, USA, pp 3-11.

Kowshik M, Ashataputre S, Kharrazi S, Kulkarni SK, Paknikar KM, Vogel W, Urban J, 2003. Extracellular synthesis of silver nanoparticles by a silver-tolerant yeast strain MKY3. Nanotechnology 14:95100.

Kroto HW, Heath JR, O'Brien SC, Curl RF, Smalley RE, 1985. C60: Buckminsterfullerene. Nature 318:162-163.

Li S, Shen Y, Xie A, Yu X, Qiu L, Zhang L, Zhang Q, 2007. Green synthe- sis of silver nanoparticles using Capsicum annuum L. extract. Green Chem. 9:852-885.

Lovley DR, Stolz JF Jr, Nord GL, Phillips EJP, 1087. Anaerobic production of magnetite by a dissimilatory iron-reducing microorganism. Nature 330:252-254.

Mann S, 1996. Biomineralization and biomimetic materials chemistry. John Wiley \& Sons, New York, USA.

Marshall AT, Haverkamp RG, Davies CE, Parsons JG, Gardea-Torresdey JL, van Agterveld D, 2007. Accumulation of gold nanoparticles in Brassica Juncea. Int. J. Phytorem. 9:197-206.

McNear DH, Peltier D, Everhart J, Chaney RL, Sutton S, Neville M, Rivers M, Sparks D, 2005. Application of quantitative fluorescence and absorption-edge computed microtomography to image metal compartmentalization in Alyssum murale. Environ. Sci. Technol. 39:2210-2218.

Memon AR, Schröder P, 2008. Implications of metal accumulation mechanisms to phytoremediation. Environ. Sci. Pollut. Res. 16:162 175.

Mesjasz-Przybylowicz J, Przybylowicz WJ, Pineda CA, 2001a. Nuclear microprobe studies of elemental distribution in apical leaves of the Ni hyperaccumulator Berkheya coddii. S. Afr. J. Sci. 97:591-593.

Mesjasz-Przybylowicz J, Przybylowicz WJ, Rama DBK, Pineda CA, 2001b. Elemental distribution in Senecio anomalochrous, a $\mathrm{Ni}$ hyperaccumulator from South Africa. S. Afr. J. Sci. 97:593-595.

Mohanpuria P, Rana KN, Yadav SK, 2008. Biosynthesis of nanoparticles: technological concepts and future applications. J. Nanopart. Res. 10:507-517.

Narayanan KB, Sakthivel N, 2011. Green synthesis of biogenic metal nanoparticles by terrestrial and aquatic phototrophic and heterotrophic eukaryotes and biocompatible agents. Adv. Colloid Interfac. 169:59-79.

Nishizono H, Kubota K, Suzuki S, Ishii F, 1989. Accumulation of heavy metals in cell walls of Polygonum cuspidatum roots from metalliferous habitats. Plant. Cell. Physiol. 30:595-598.

Park Y, Hong YN, Weyers A, Kim YS, Linhardt RJ, 2011. Polysaccharides and phytochemicals: a natural reservoir for the green synthesis of gold and silver nanoparticles. IET Nanobiotechnol. 5:69-78.

Pérez-de-Luque A, Rubiales D, 2009. Nanotechnology for parasitic plant control. Pest Manag. Sci. 65:540-545.

Perry CC, Keeling-Tucker T, 2003. Model studies of colloidal silica precipitation using biosilica extracts from Equisetum telmateia. Colloid Polym. Sci. 281:652-664.

Porter AL, Youtie J, 2010. How interdisciplinary is nanotechnology? J. Nanopart. Res. 11:1023-1041.

Prathna TC, Mathew L, Chandrasekaran N, Raichur AM, Mukherjee A, 2010. Biomimetic synthesis of nanoparticles: science, technology \& applicability. In: A. Mukherjee (ed.) Biomimetics learning from nature. InTech Publisher, pp 1-20.

Rafols I, Meyer M, 2010. Diversity and network coherence as indicators of interdisciplinarity: case studies in bionanoscience. Scientometrics 82:263-287.

Rai A, Singh A, Ahmad A, Sastry M, 2006. Role of halide ions and temperature on the morphology of biologically synthesized gold nanotriangles. Langmuir 22:736-741.

Rai M, Yadav A, Gade A, 2008. Current trends in phytosynthesis of metal nanoparticles. Crit. Rev. Biotechnol. 28:277-284.

Ramsden JJ, 2005. What is nanotechnology? Nanotechnol. Percept. 1:317.

Robinson BH, Bañuelos B, Conesa HM, Evangelou MWH, Schulin R, 2009. The phytomanagement of trace elements in soil. Crit. Rev. Plant Sci. 28:240-266.

Rodriguez E, Cruz-Jimenez G, Parsons JG, Peralta-Videa JR, RomeroGonzalez J, 2007. Potential of Chilopsis linearsis for gold phytomining: using XAS to determine gold reduction and nanoparticle for- 
mation within plant tissues. Int. J. Phytorem. 9:133-147.

Salt DE, Smith RD, Raskin I, 1998. Phytoremediation. Annu. Rev. Plant Physiol. Plant Mol. Biol. 49:643-668.

Shapira P, Wang J, 2010. Follow the money. Nature 468:627-628

Sharma NC, Gardea-Torresdey JL, Nath S, Pal T, Parsons JG, Sahi SV, 2007. Synthesis of plant mediated gold nanoparticle and catalytic role of biomatrix embedded nanomaterials. Environ. Sci. Technol. 936: 2929-2933.

Sharon M, Choudhary AK, Kumar R, 2010. Nanotechnology in agricultural diseas and food safety. J. Phytol. 2:83-92.

Shiv Shankar S, Ahmad A, Pasricha R, Sastry M, 2003a. Bioreduction of chloroaurate ions by geranium leaves and its endophytic fungus yields gold nanoparticles of different shapes. J. Mater. Chem. 13:1822-1826.

Shiv Shankar S, Ahmad A, Sastry M, 2003b. Geranium leaf assisted biosynthesis of silver nanoparticles. Biotechnol. Prog. 19:16271631.

Shiv Shankar S, Rai A, Ahmad A, Sastry M, 2004. Rapid synthesis of Au, $\mathrm{Ag}$, and bimetallic Au core-Ag shell nanoparticles using neem (Azadirachta indica), leaf broth. J. Colloid. Interf. Sci. 275:496-502.

Shiv Shankar S, Rai A, Ahmad A, Sastry M, 2005. Controlling the optical properties of lemongrass extract synthesized gold nanotriangles and potential application in infrared-absorbing optical coat- ings. Chem. Mater.17:566-572.

Singaravelua G, Arockiamaryc JS, Ganesh Kumar V, Govindarajua KA, 2007. Novel extracellular synthesis of monodisperse gold nanoparticles using marine alga, Sargassum wightii Greville. Colloids Surfaces B. 57:97-101.

Skinner HCW, Jahren AH, 2003. Biomineralization. In: W.H. Schlesinger (ed.) Treatise on Geochemistry. Elsevier, Amsterdam, The Netherlands, pp 117-184.

Starnes D, Jayjain A, Sahi S, 2010. In planta engineering of gold nanoparticles of desirable geometries by modulating growth conditions: an environment-friendly approach. Environ. Sci. Technol. 44:7110-7115.

USEPA, 2007. Nanotechnology White Paper - External Review Draft. U.S. Environmental Protection Agency. Document no. EPA 100/B07/001.

Weiner S, Dove PM, 2003. An overview of biomineralization and the problem of the vital effect. In: P.M. Dove, S. Weiner and J.J. De Yoreo (eds.) Biomineralization, vol. 54. Mineralogical Society of America Publ., Washington, DC, USA pp 1-31.

Youtie Y, Shapira P, Porter AL, 2008. Nanotechnology publications and citations by leading countries and blocs. J. Nanopart. Res. 10:981986. 